\title{
Is it worth investing in cryptocurrency?
}

\author{
Tatiana Antipova ${ }^{1 *}$ \\ ${ }^{1}$ Institute of Certified Specialists, Perm, Russia
}

\begin{abstract}
Bitcoin price was exceed 60 thousand USD per one Bitcoin in March 2021. This fact manifested a general trend of rising cryptocurrency values during COVID-19 pandemic. Hence the related question, is it worth investing in cryptocurrency? The answer to this question depends on many factors, one of the decisive ones is the high volatility of cryptocurrency. Current work considers volatility and profitability of cryptocurrency, and discusses how to determine volatility and profitability of cryptocurrencies and its importance in investing. In addition, the profitability/losses of cryptocurrency transactions are analysed. If cryptocurrency will be stable in the future, then it is easily accepted through worldwide and in the long run, people would have more trust to the cryptocurrency and its usability.
\end{abstract}

\section{Introduction}

In prior work [1] the birth of cryptocurrencies, their definition and classification are considered. The crisis caused by COVID-19 pandemic $[2,3]$ has increased/strengthened settlement in cryptocurrency and the value of cryptocurrencies has skyrocketed. Why cryptocurrency became so popular? Some scientists $[4,5]$ document three main determinants. First, the current use of virtual currency to make real payments. Second, the decision of forward-looking investors to buy virtual currency (thereby effectively reducing its supply) given expected growth in virtual currency transactions. Third, the elements that jointly drive consumer adoption and merchant acceptance of virtual currency, which determine expected long-term growth in usage.

Considering that bitcoin was worth a few cents at the beginning of its creation and now excels thousands of USD per unit, it seems that investing in bitcoin is a very profitable. Accordingly, the hype of mining - cryptocurrency mining is akin to the Gold Rush. At the beginning of January 2021, Bitcoin rose to $\$ 30,000$, it was already worth $\$ 50,000$ on February 15 , and $\$ 58,000$ on February 22 . After that, the rapid growth was interrupted, but not for long. During the day on March 12-13, 2021, the world's main cryptocurrency, Bitcoin, rose by almost $\$ 4,000$ and crossed the $\$ 60,000$ mark. But we should take into account many other factors that make investment in cryptocurrency very risky and they are: high volatility; unstable profitability and losses; costly expenses on electricity and equipment, and many others. Some of them are considered in the followed parts of this paper.

As we know, the unit of any cryptocurrency is a set of symbols and mining cryptocurrency is akin to picking a cipher to a safe. If the computer has found a given set of characters belonging to a cryptocurrency unit - the cryptocurrency is found. Since initially there was a

* Corresponding author: antipovatatianav@gmail.com 
limited number of bitcoins created - 21 million units, it is clear that the balance is decreasing daily and from this point of view bitcoins are getting harder to find and should only get more expensive day by day. But high volatility, high bitcoin cashing fees and the possibility of losses when buying bitcoin are worrisome. Therefore, we should first understand what cryptocurrency volatility is and how it affects profitability/profitability of cryptocurrency investments.

\section{Volatility and Profitability of cryptocurrency mining}

Volatility is the degree of change in the value of an asset over a certain period (Fig.1). In other words, volatility is characterized by the degree of price change of an asset over a certain period of time. It is usually measured by the volatility index.
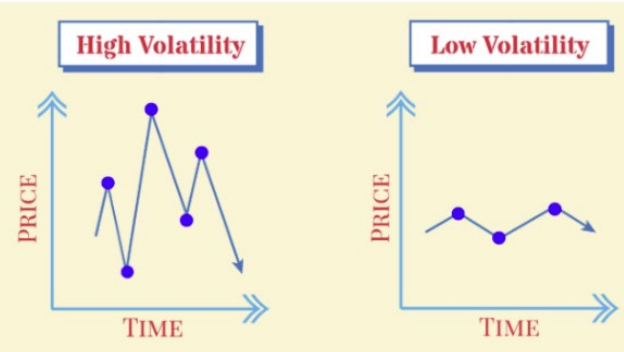

Fig. 1. The essence of Volatility. Source: masterthecrypto.com.

When determining the volatility for the year on the basis of available daily data, a significant error is allowed because the standard deviation follows the process of "mean reversion" (return to the average). In this case, in the long run, volatility fluctuates around the average value (the minimum values increase, and the maximum values decrease, tending to approach the average). That is why we take the time interval of 10 trading days as a basis for volatility calculation, the year duration - the number of trading days - is taken as 250 days (taking into account weekends and holidays). Relative volatility is determined as a standard deviation of daily rate changes within 10 days, divided by $\sqrt{ } 10 / 250$, which is equal to 0.2 [7].

The most common way to get cryptocurrency is to mine it via hardware. The most expensive resources for mining are the mining farm and the electricity to power it. The high price of cryptocurrency is due to the need to purchase several huge computers with a quality video card at least several terabytes of capacity, as well as the incredible amount of electricity spent on the mining process. In addition, before starting the cryptocurrency's mining investor must have a good knowledge of cryptocurrencies, blockchain, mining, and many other things.

Among many kind of cryptocurrencies Bitcoin has become one of the most famous and by far the largest cryptocurrency in terms of market capitalization [6] so we can consider volatility of price on Bitcoin example. 


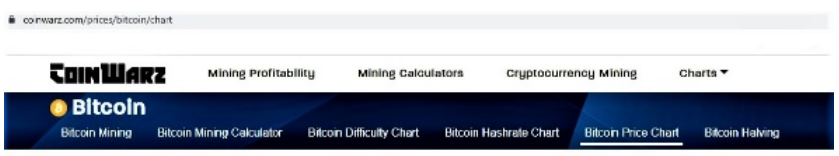

\section{B Bitcoin Price Chart}

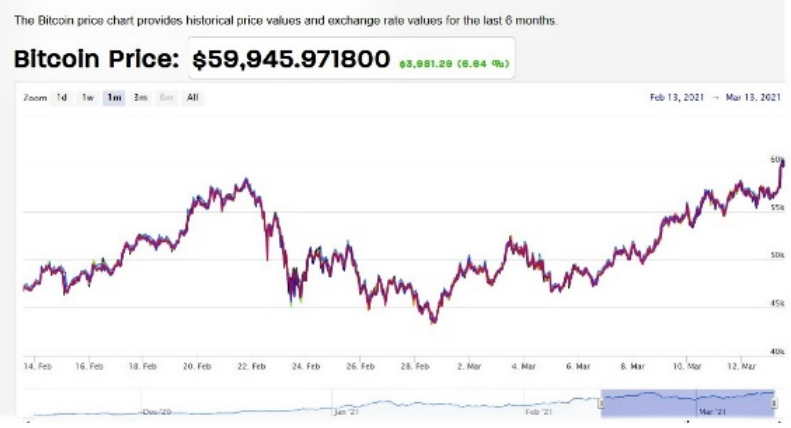

Fig. 2. Bitcoin Price for one month period 13.02.2021 - 13.03.2021. Source:

https://www.buybitcoinworldwide.com/volatility-index/.

On Fig.2 we can see that Bitcoin Price changes many times a day, minutes, seconds and nobody able to say what price will be reach on the next second. To understand approximately behavior of this price it is needed long-term observation.

The result of calculating the average price and volatility of bitcoin for four-years period 13.03.2017 - 13.03.2021 is shown in Fig 3.

The Bitcoin Volatility Index

$\begin{array}{ll}\text { Latest 30-Day Estimate } & \text { Latest 60-Day Estimate } \\ 4.14 \% & 5.05 \%\end{array}$

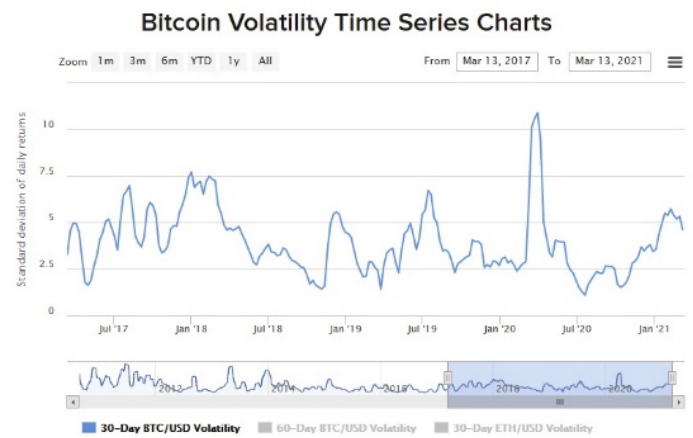

Fig. 3. Bitcoin Volatility Index for four years period 13.03.2017 - 13.03.2021.

Source: https://www.buybitcoinworldwide.com/volatility-index/.

Comparing Fig. 1 - Fig.3 data we can see that bitcoin has very high index of volatility. So, it means that the investment in this active is very risky. Will it be profitable?

Let's consider the profitability/loss of Cryptocurrency Mining Results (Table 1). We analysed data of 15 Cryptocurrencies which were on the first position at the beginning of this 
study on 03.09.2019. It is necessary to note that in Table 1 columns "Profit or (Loss) per day" the values shown are net of electricity costs.

Table 1. Cryptocurrency Mining Results

\begin{tabular}{|c|c|c|c|c|c|}
\hline \multirow{2}{*}{$\begin{array}{c}\text { Posit } \\
\text { ion }\end{array}$} & \multirow{2}{*}{$\begin{array}{l}\text { Cryptocurrency (in current } \\
\text { profitability position, as of } \\
01.05 .2021 \text { ) }\end{array}$} & \multirow{2}{*}{\begin{tabular}{|c|} 
Est. Coins (24Hr Avg) as \\
of 03.09.2019/13.03.2021/ \\
01.05 .2021 \\
\end{tabular}} & \multicolumn{3}{|c|}{ Profit or (Loss) per day } \\
\hline & & & 03.09.2019 & 13.03.2021 & 01.05 .2021 \\
\hline 16 & Vertcoin (VTC) & $0.7054 / 134.6891 / 5.9012$ & $(\$ 1.25)$ & $\$ 86.59$ & $\$ 7.54$ \\
\hline 3 & Peercoin (PPC) & $17.7521 / 82.0981 / 39.5422$ & $\$ 2.35$ & $\$ 37.19$ & $\$ 39.86$ \\
\hline 5 & BitcoinCash $(\mathrm{BCH})$ & $0.0196 / 0.0742 / 0.0394$ & $\$ 1.90$ & $\$ 36.16$ & $\$ 32.00$ \\
\hline 7 & Bitcoin (BTC) & $0.0005 / 0.0006 / 0.0006$ & $\$ 1.95$ & $\$ 30.73$ & $\$ 26.21$ \\
\hline 10 & Florincoin (FLO) & $44.1646 / 354.3339 / 296.965$ & $(\$ 1.97)$ & $\$ 22.75$ & $\$ 20.28$ \\
\hline 11 & Einsteinium (EMC2) & $20.4254 / 41.5608 / 43.4245$ & $(\$ 1.87)$ & $\$ 11.89$ & $\$ 16.14$ \\
\hline 8 & Ethereum-Classic (ETC) & $0.4076 / 0.9783 / 0.6200$ & $\$ 0.95$ & $\$ 11.39$ & $\$ 22.27$ \\
\hline 14 & Litecoin (LTC) & $0.0281 / 0.0567 / 0.0511$ & $(\$ 1.64)$ & $\$ 7.89$ & $\$ 8.90$ \\
\hline 12 & Zcash (ZEC) & $0.0612 / 0.0528 / 0.0664$ & $\$ 1.66$ & $\$ 4.11$ & $\$ 13.19$ \\
\hline 13 & Horizen $(\mathrm{ZEN})$ & $0.5993 / 0.1559 / 0.1281$ & $\$ 1.59$ & $\$ 3.11$ & $\$ 12.41$ \\
\hline 19 & Feathercoin (FTC) & $3.2216 / 5.8561 / 4.7740$ & $(\$ 0.91)$ & $(\$ 0.71)$ & $(\$ 0.76)$ \\
\hline 18 & Dash (DASH) & $0.0167 / 0.0133 / 0.0093$ & $(\$ 1.85)$ & $(\$ 0.86)$ & $(\$ 0.63)$ \\
\hline 20 & Monacoin (MONA) & $0.0137 / 0.0044 / 0.0059$ & $(\$ 1.42)$ & $(\$ 1.43)$ & $(\$ 1.42)$ \\
\hline 17 & Monero (XMR) & $0.0422 / 0.0015 / 0.0013$ & $\$ 0.88$ & $(\$ 1.82)$ & $(\$ 0.51)$ \\
\hline 2 & LitecoinCash (LCC) & $366.1717 / 3771.57 / 2,387.11$ & $\$ 1.69$ & $(\$ 2.11)$ & $\$ 49.17$ \\
\hline
\end{tabular}

Source: Author's compilation from https://www.coinwarz.com/cryptocurrency.

As we can see on Table 1, Profitability of cryptocurrencies' mining is very unstable and unpredictable. Some cryptocurrencies were losses (e.g. Vertcoin, Florincoin, Einsteinium, and Litecoin) on 03.09.2019 and became profitable on 13.03.2021 and 01.05.2021. The most interesting is LitecoinCash (LCC) behaviour: it was profitable on 03.09.2019 with fourth position, losses on 13.03.2021, and had got highest of studied cryptocurrencies profit on 01.05.2021 with second position. So, there is no possible to predict which one will be profitable, which - losses. In addition, we can conclude that Profit per day is not so much: from $\$ 7.54$ to $\$ 86.59$ and is well below the average daily wage for a manager. And it proves once again that investing in cryptocurrency is not very profitable.

The similar point of view can be visible from other compatible data. Table 2 shows the variety of cryptocurrencies' types when we defined Top Gainers and Top Losers for two occasionally days at the beginning and the end of this investigation.

Table 2. Top Gainers and Top Losers on 03.09.2019 and on 01.05.2021

\begin{tabular}{|c|c|c|c|c|c|c|c|c|c|}
\hline \multicolumn{5}{|c|}{ Top Gainers on 03.09.2019 } & \multicolumn{5}{|c|}{ Top Losers on 03.09.2019 } \\
\hline \multicolumn{3}{|l|}{ Biggest Gainers* } & 1h & \begin{tabular}{l|l|}
$24 \mathrm{~h}$ & $7 \mathrm{~d}$
\end{tabular} & & & \multirow{2}{*}{$\begin{array}{c}7 \mathrm{~d} \\
\% 24 \mathrm{~h}\end{array}$} \\
\hline \# Name & Symbol & Volume (24h) & Price & $\% 24 h$ & \# Name & Symbol & Volume (24h) & Price & \\
\hline 1 ERC20 & ERC20 & $\$ 159741$ & $\$ 0,061552$ & $104.19 \%$ & 1 國 Custody Token & cust & $\$ 669184$ & $\$ 0,001821$ & $-95.51 \%$ \\
\hline 2 Almeela & KZE & $\$ 77072$ & $\$ 0,030379$ & $94.51 \%$ & 2 - Japan Content Token & JCT & $\$ 249801$ & $\$ 0,132666$ & $-42.73 \%$ \\
\hline 3 ๑) QuadrantProtocol & EQUAD & $\$ 933369$ & $\$ 0,001659$ & $82.49 \%$ & $3 \bullet$ Jewel & $J W L$ & $\$ 228854$ & $\$ 0,102465$ & $-35.78 \%$ \\
\hline $4 \not$ MINDOL & MIN & $\$ 4442310$ & $\$ 0,244742$ & $81.93 \%$ & $4 \Delta$ Business Credit Allian... & BCAC & $\$ 151191$ & $\$ 0,006539$ & $-33.04 \%$ \\
\hline 5 ELACoin & ELAC & $\$ 217783$ & $\$ 0,005862$ & $48.92 \%$ & 5 Spiking & SPIKE & $\$ 1721300$ & $\$ 0,002691$ & $-29.71 \%$ \\
\hline $6 \cup$ Tokentox & TBX & $\$ 55623$ & $\$ 0,019451$ & $48.56 \%$ & 6 Aidos Kuneen & ADK & $\$ 1751783$ & $\$ 3,71$ & $.26 .34 \%$ \\
\hline $7 \bullet$ Tratok & TRAT & $\$ 1521358$ & $\$ 0,006890$ & $48.30 \%$ & 7 Swace & SWACE & $\$ 57421$ & $\$ 0,002900$ & $-21.83 \%$ \\
\hline $8 \star Z E O N$ & ZEON & $\$ 122557$ & $\$ 0,000026$ & $41.39 \%$ & 8 EMOGI Network & LOL & $\$ 9608905$ & $\$ 0,003860$ & $-14.31 \%$ \\
\hline $9 \odot$ Agoras Tokens & AGRS & $\$ 75744$ & $\$ 0,274252$ & $38.64 \%$ & 9 Tokoin & токо & $\$ 614272$ & $\$ 0,137675$ & $-13.73 \%$ \\
\hline 10 TraDove B2BCoin & $\mathrm{BBC}$ & $\$ 210227$ & $\$ 0,000822$ & $38.64 \%$ & 10 월 Caspian & CSP & $\$ 162365$ & $\$ 0,005666$ & $-13.38 \%$ \\
\hline 11 (1) Verasity & VRA & $\$ 2056345$ & $\$ 0,000659$ & $36.30 \%$ & $11 \mathbf{Z}$ ZeuxCoin & Zuc & $\$ 201246$ & $\$ 0,024177$ & $-1257 \%$ \\
\hline $12 \bigcirc$ GreenPower & GRN & $\$ 171341$ & $\$ 0,009018$ & $35.52 \%$ & 12 eosDAC & EOSDAC & $\$ 75907$ & $\$ 0,004151$ & $-12.51 \%$ \\
\hline $13 \Rightarrow \mathrm{DADI}$ & DADI & $\$ 61039$ & $\$ 0,064299$ & $34.78 \%$ & $13-$ GAMB & GMB & $\$ 372760$ & $\$ 0,000119$ & $-12.49 \%$ \\
\hline $14+$ Sparkle & SPRKL & $\$ 259135$ & $\$ 0,074535$ & $34.49 \%$ & $14 \bigcirc$ Dragon Coins & DRG & $\$ 86174$ & $\$ 0,127411$ & $-11.99 \%$ \\
\hline 15 P PLANET & PLA & $\$ 1019420$ & $\$ 0,119358$ & $31.81 \%$ & 153 Restart Energy MWAT & MWAT & $\$ 71451$ & $\$ 0,022951$ & $-11.58 \%$ \\
\hline & ners & .05 .20 & & & Top & S on & .2021 & & \\
\hline
\end{tabular}




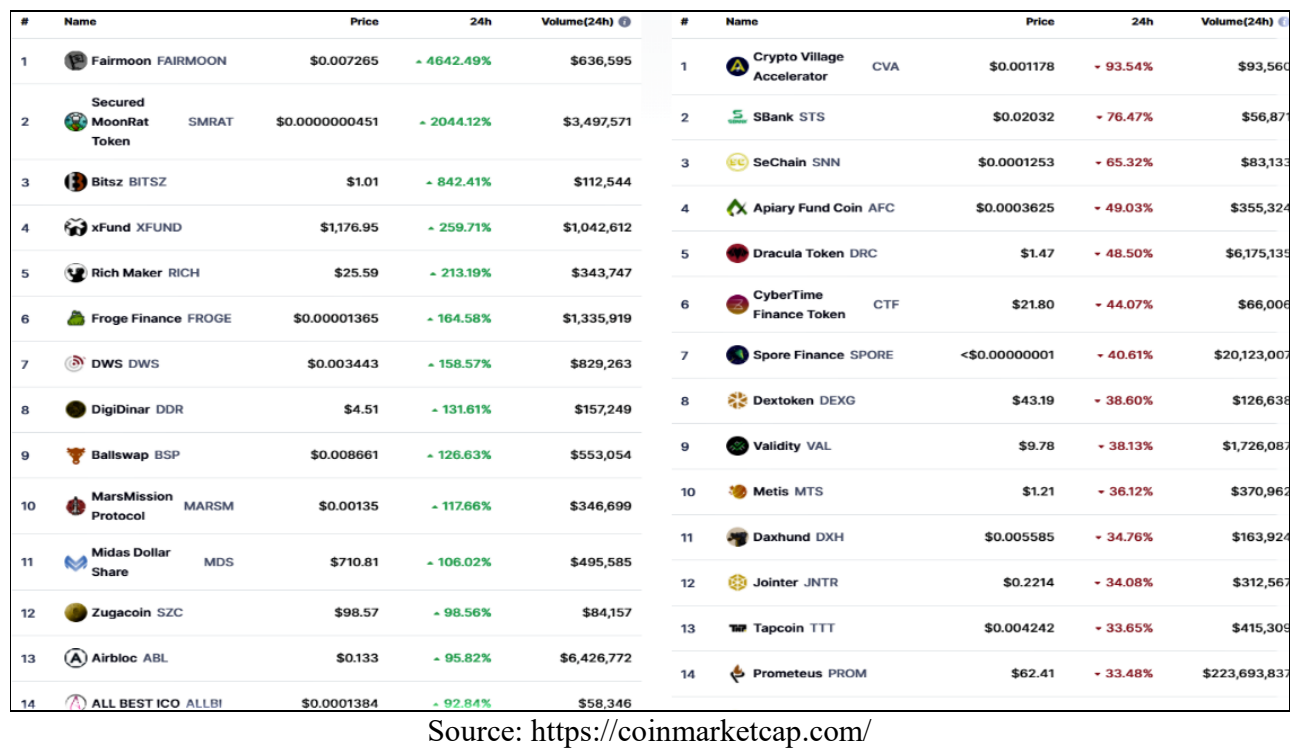

From Table 2 data we can see variety of cryptocurrency names. This is because each cryptocurrency is created by different individuals and everyone calls their cryptocurrency whatever they want. Also, Table 2 does not consist data about cryptocurrency analyzed in Table 1. One reason is that the data was analysed from different websites (e.g. https://coinmarketcap.com, https://www.coinwarz.com,https://www.buybitcoinworldwide.c om ). And that means that different websites have data on different cryptocurrencies that have little overlap with each other. Thus, the sheer number of different cryptocurrencies (over ten thousand names) allows for data that has almost no overlap with each other. This suggests that a systematic analysis of all cryptocurrencies is very problematic. There is only some sketchy information that can be found on many different sources (websites). Therefore, no systematic conclusion about the profitability of investing in cryptocurrencies can be drawn.

Another factor that affects investing in cryptocurrency is the time to mine and obtain a unit of cryptocurrency. Again, the author is not claiming a systematic conclusion, as the vast variety of cryptocurrencies can produce completely contradictory data. In my opinion, systematising data on all cryptocurrencies is very problematic at this stage. Now it seems possible to provide only some examples of some cryptocurrency's mining experiences.

For example, as of Saturday, March 13, 2021, mining Bitcoin (BTC) was still profitable based on the mining hardware hashrate of $110.00 \mathrm{TH} / \mathrm{s}$, consuming 3,250 watts of power at $\$ 0.05$ per $\mathrm{kWh}$, and a block reward of $6.25 \mathrm{BTC}$ at $\$ 59,915.58$ (BTC to USD). Also, it is important to point out that with these characteristic (hashrate of $110.00 \mathrm{TH} / \mathrm{s}$ consuming $3,250.00$ watts of power at $\$ 0.05$ per $\mathrm{kWh}$, and a block reward of $6.25 \mathrm{BTC}$ ) to mine 1 Bitcoin would take $\mathbf{1 , 5 5 0 . 8}$ days. After deducting mining power costs and mining fees, the final daily Bitcoin mining profit is $\mathbf{\$ 3 0 . 7 3}$ Bitcoin to USD. Bearing in mind that amount of bitcoin is limited (no more than $21 \mathrm{mln}$ units) the cost of bitcoin would increase time to time in general but this increasing will not smooth and uninterrupted. Mining profitability can change very quickly in case such factors as difficulty increases and decrease; block reward increases and decrease, etc. [8-14].

So, investing in 1 Bitcoin would take more than four (4!) years with daily profit about $\$ 30$. Actually, for the same period of time you can grow up child(s) or many trees. And in this light, from this point of view, investing in cryptocurrency seems a very dubious endeavour. 


\section{Conclusion}

Due to high volatility cryptocurrency rises and falls in value quickly and aggressively, many times a day. In this regard, person can either make a huge profit, or lose everything and stay with nothing in one milli second. Therefore, the decision to invest in cryptocurrency is made by each person individually. It all depends on one's risk appetite that requires nerves of steel and iron stamina. Individuals who afraid to take a risk avoid investments with high volatility because they are more concerned about stability and preservation of their wealth. Those people who participate in crypto trading are commonly referred to as risk-averse. According to the Blockchain Capital Harris Poll in the U.S., about $60 \%$ of bitcoin buyers are the $2000 \mathrm{~s}$ generation. These statistics prove that young people are more interested in risky investments. And because the cryptocurrency market is a highly volatile market, it is a double-edged sword: it has the potential to generate tidy profits, but each participant also faces a high risk of losing a significant share of capital.

Author never cease to be amazed at how very reasonable people would take unreasonable financial risks, both unknowingly and knowingly. A common characteristic was that, in retrospect, they would remember more the gains than the losses. In addition, in this study author have not looked at cryptocurrency as a way of escaping taxation and gaining some freedom from any power. In the author's view, living in society and being free from society is very problematic, so these aspects are the limitation of this study. Ultimately, every investor needs to know his or her measure of risk appetite in order to make a sound assessment of his or her options.

To conclude, this paper considered the most common factors influence the attraction on investing in cryptocurrency: Volatility, Profitability, and Mining time. In the future would be possible to research cryptocurrency as a means of payment.

\section{References}

1. Antipova T., Emelyanova I. Cryptocurrency in Digital Wallet: Pros and Cons. In: Antipova T., Rocha A. (eds), Digital Science, AISC, 850, 313 - 322 (2019). https://doi.org/10.1007/978-3-03002351-5 36 .

2. Antipova T. (2021) Coronavirus Pandemic as Black Swan Event. In: Antipova T. (eds) Integrated Science in Digital Age 2020. ICIS 2020. LNNS, 136, 356-366. https://doi.org/10.1007/978-3-03049264-9 32.

3. Antipova T. (2021) Digital View on COVID-19 Impact. In: Antipova T. (eds) Comprehensible Science. ICCS 2020. Lecture Notes in Networks and Systems, vol 186, pp. 155-164. Springer, Cham. https://doi.org/10.1007/978-3-030-66093-2 15 .

4. Botoş, H. M. (2017). Bitcoin intelligence - business intelligence meets crypto currency. Iasi: Alexandru Ioan Cuza University of Iasi, Centre for European Studies. Retrieved from http://0search.proquest.com.www.elgar.govt.nz/docview/1962594044? accountid $=40858$.

5. Bolt W., Van Oordt, M.R.C. On the Value of Virtual Currencies. Journal of Money, Credit and Banking, 52(4), 835-862 (2019). DOI: https://doi.org/10.1111/jmcb.12619.

6. López-Cabarcos M. Á., et al. Bitcoin volatility, stock market and investor sentiment. Are they connected? Finance Research Letters, 38, (2021), 101399, https://doi.org/10.1016/j.frl.2019.101399.

7. Krylov G.O., Lisitsyn A.Yu., Polyakov L.I. Comparative Analysis of Volatility of Cryptocurrencies and Fiat Money. Finance: theory and practice, 22(2), 66-89 (2018). DOI: https://doi.org/10.26794/2587-5671-2018-22-2 .

8. URL: https://www.coinwarz.com/mining/bitcoin/calculator .

9. Bouri, E, Gil-Alana, LA, Gupta, R, Roubaud, D. Modelling long memory volatility in the Bitcoin market: Evidence of persistence and structural breaks. Int $J$ Fin Econ. 2019; 24: 412- 426. https://doi.org/10.1002/ijfe.1670. 
10. Cicvarić, B.C., 2020. Volatility of cryptocurrencies. Notitia 6, 13-23. https://doi.org/10.32676/n.6.1.2 .

11. Katsiampa, P., Corbet, S., Lucey, B., 2019. High frequency volatility co-movements in cryptocurrency markets. Journal of International Financial Markets, Institutions and Money 62, 35-52. https://doi.org/10.1016/j.intfin.2019.05.003 .

12. Caporale G.M., Zekokh T. Modelling volatility of cryptocurrencies using Markov-Switching GARCH models. Research in International Business and Finance 48,143-155(2019). https://doi.org/10.1016/j.ribaf.2018.12.009.

13. URL: https://www.buybitcoinworldwide.com.

14. URL: $\underline{\text { https://coinmarketcap.com. }}$ 